\title{
Using Financial Information to Differentiate Failed vs. Surviving Finance Companies in Thailand: An Implication for Emerging Economies*
}

\author{
Obeua S. Persons \\ Rider University, U.S.A.
}

This article combines qualitative and quantitative information from financial statements and auditors' reports with logistic models to differentiate failed from surviving finance companies in Thailand. Failed companies are those that were forced to suspend their operations in mid-1997. The results indicate that auditors' reports from the 1996 financial statements did not differentiate failed from surviving finance companies. On the other hand, the logistic regression models indicate that failed finance companies had lower profitability, lower foreign borrowing possibly due to their poorer credit rating, lower management quality, and smaller size. These models have relatively high predictive ability for failed finance companies and low expected costs of misclassification (JEL G21, M41).

Keywords: CAMEL, emerging economies, financial failure, logistic model, Thailand.

\section{Introduction}

Thailand recently experienced severe economic and financial problems mainly as a result of misguided national finance policies, inefficient operational and investment decisions of its financial sector, and very weak supervisory and regulatory standards (Boorman 1999). To alleviate the problem of severely tight money supplies, the Thai

*The author thanks Kuakul Srichandrabhandhu at the Bank of Thailand for providing a copy of the Bank of Thailand's reports. Funding from the Davis Fellowship of College of Business Administration at Rider University is gratefully acknowledged.

(Multinational Finance Journal, 1999, vol. 3, no. 2, pp. 127-145)

CMultinational Finance Society, a nonprofit corporation. All rights reserved. DOI: $10.17578 / 3-2-3$ 
government had to obtain a $\$ 17$ billion loan from the International Monetary Fund $(I M F)$. In response to the requirements of the $I M F$, the Bank of Thailand, which is the main regulator of Thai financial institutions, had to suspend the operations of 58 finance companies in mid-1997. This led to the loss of thousands of jobs and, more alarmingly, the loss of public confidence in the financial sector of the country.

The purpose of this article is to statistically differentiate failed finance companies from surviving companies using financial variables from 1993-1996 financial statements and their related notes. Failed finance companies are defined as those which were forced by the Bank of Thailand (BOT) to suspend their operations. The BOT based its suspension decision on CAMEL criteria, which are capital adequacy, asset quality, management quality, earnings ability, and liquidity. Therefore, this article identifies the financial variables using CAMEL criteria as well as previously published articles and the examination of the reasons for the problems in Thai financial institutions.

The Report of the Ministry of Finance and the Bank of Thailand (October 14, 1997) and the Supervision Report 1996-97 of the Bank of Thailand indicate several reasons for the problems in Thai financial institutions. The first reason pertains to trade deficits, heavy foreign borrowing, and shifting economic environment. The fast-growing Thai economy before 1996 created a high demand for imported goods and services which outpaced the exports, leading to large trade deficits. Thailand's heavy foreign borrowing to help finance its imports, which was not such a burden during the period of strong economic growth, became a problem during an economic slowdown starting in 1996. The second reason is excessive foreign capital inflows over the five-year period before 1996, leading to an over-expansion of credits into real estate development and securities investments. This overactive real estate investment led to a rapid increase in property prices and, in turn, an overbuilding of real estate development and overpricing of real estate properties. Several finance companies also sought additional financing by issuing bonds in the international markets, exposing them to foreign exchange risk. The third reason is inefficient investment decisions of finance companies' management. Loans were extended to real estate projects which were not yielding sufficiently high returns. Several finance companies either relied on overvalued collateral without a thorough understanding of the business of the borrowers, or relied too heavily on the borrowers' status as listed companies on the stock market 
and made loans without collateral. Loans were also granted for purchases of stocks, including those that did not have sufficient market liquidity. The fourth reason is that the Bank of Thailand did not have sufficient requirements to assure accurate accounting measurement and valuation of Thai finance companies. In particular, there were no rules regarding accrued interest on overdue loans, the loan-to-deposit ratio, and a provision for substandard loans and doubtful loans. ${ }^{1}$ The fifth reason is inadequate financial disclosure. Particularly, finance companies failed to disclose the use of short-term liabilities to finance long-term investments and to report loans by categories or by maturity of loans, making it impossible for investors to assess the diversification and the risk of loan investments. This mismatch of liabilities and investments intensified the finance companies' liquidity problems when domestic and foreign creditors questioned the debt-paying ability of these companies and started to move money out of Thailand.

These five reasons for the problems in Thai financial institutions are likely to be shared by other emerging economies that experienced similar financial crises shortly after Thailand did. In all, $\$ 120$ billion has been committed by the IMF, the World Bank, the Asian Development Bank, and others to bail out these countries (Boorman 1999). This colossal magnitude of problems necessitates the development of early warning models that could predict potential failure of financial institutions in emerging economies. The primary objective of this article is to use well-known statistical techniques for financial distress prediction to develop such models based upon Thai finance companies' data. In particular, this article uses the univariate Wilcoxon rank-sum tests and the multivariate logistic regression to ex-post differentiate failed and surviving finance companies. The selection of the explanatory variables in the parsimonious logistic models is accomplished using Akaike's Information Criterion (AIC). The predictive ability of these models is assessed using the jackknife method and the optimal cutoff probability.

The remaining part of the article is organized as follows. Section II describes the sample collection procedure and financial variables used. Section III discusses empirical models for predicting failed Thai finance firms. Section IV reports predictive ability of the models. Section V

1. Substandard loans are loans for which debtors failed to pay interest on schedule. Doubtful loans are those for which debtors failed to pay interest for 12 consecutive months or more. 
presents conclusions and implications for other emerging economies.

\section{Sampling and Variables Used}

\section{A. Sampling Procedure}

Before 1997, Thailand had a total of 91 finance companies. In mid1997, the Bank of Thailand suspended operations of 58 finance companies: 16 companies on June 27, 1997, and another 42 companies on August 5, 1997. ${ }^{2}$ The remaining 33 companies were not suspended. The failure rate is, therefore, exceptionally high at $63.7 \%$. Out of the 58 failed companies, only 26 were listed on the Thai stock market. Out of the 33 surviving companies, only 15 were listed on the stock market. Only these listed companies have their financial reports available to the public. Therefore, the sample in this article includes 41 finance companies: 26 failing and 15 surviving. The failure rate in this sample is $63.4 \%$, i.e., virtually the same as the rate in the universal population.

Financial data for these 41 sample firms was collected from the $I$ SIMS database of the Stock Market of Thailand (SET). I-SIMS is an abbreviation for Integrated - SET Information Management System. It provides relevant financial data of all companies listed in the Stock Market of Thailand. This data includes company-specific information such as financial statements, footnotes to the statements, and auditors' reports. Three out of four years of data (1994-1996) was collected from this database in the library of the Stock Market of Thailand. Random verification of the information from the database against the hard copy of annual reports indicates high accuracy of database information. Data for 1993 was extracted from the I-SIMS CD-ROM subsequently purchased from the Stock Market of Thailand. The year 1993 is the earliest year in the CD-ROM which provides five-year data ending on May 31, 1998.

\section{B. Variables Used}

The 1997 Supervision Report of the Bank of Thailand indicates that the $B O T$ relied on the CAMEL criteria in its decision to suspend the finance companies' operations. CAMEL is an acronym for Capital adequacy,

2. Two of these companies recently restarted their operations after their parent companies helped them raise needed capital. 
Asset quality, Management quality, Earnings ability, and Liquidity. CAMEL has been used by the Federal Deposit Insurance Corporation and regulators of financial institutions worldwide. These criteria were also used by several previous articles to predict bank failures (Thompson [1991]; Tam and Kiang [1992]; Barr and Siems [1994]; Hooks [1995]; Gonzalez-Hermosillo, Pazarbasioglu, and Billings [1997]). Therefore, this article uses the CAMEL criteria to identify potential variables for the models. Based on previously published articles and the examination of the causes of the problems in Thai financial institutions, this article also uses two other criteria: firm size and reliance on foreign-funded sources. In sum, these seven criteria lead to nine variables. The criteria and their related variables are described below.

\section{Capital Adequacy}

This criterion is measured by the ratio of equity capital to total loans (CAPITAL). Similar to Barr and Siems (1994), this article uses total loans instead of total assets. This is because loans of finance companies are assets with the highest potential of unanticipated losses, and an adequate level of capital must be maintained to absorb these unanticipated losses. The use of this ratio is also in accordance with the Bank of Thailand's guidelines. A higher ratio reflects higher capital adequacy and lower probability of failure.

\section{Asset Quality}

Asset quality is negatively related to asset risk or the probability of impairment in assets' value. This article uses two variables to proxy for asset quality: total loans to total assets (LOAN/TA) and nonperforming loans to total loans $(B A D L O A N){ }^{3}$ The total loans-to-total assets ratio alleviates the problem that finance companies may have underestimated their nonperforming loans. Higher ratios mean poorer asset quality and higher probability of failure. LOAN/TA was used by Wheelock and Wilson (1994), Hooks (1995), and Hwang and Lee (1997). BADLOAN was used by Gonzalez-Hermosillo, Pazarbasioglu, and Billings (1997).

3. Several previous articles (Tam and Kiang [1992]; Cole and Gunther [1995]; Gonzalez-Hermosillo, Parazbasioglu, and Billings [1997]) also use the concentration of a bank's loan portfolio to proxy for asset quality. For Thailand, the large exposure to the real estate sector is a major cause for the failure. Unfortunately, Thai finance companies did not disclose their loans by any categories. Therefore, it is impossible to use such proxy. 


\section{Management Quality}

It is difficult to measure the quality of management because it involves qualitative issues such as the aptitude for risk-taking, the compliance to regulatory procedures, and the development of sound internal control. Tam and Kiang (1992) stated that the management quality would eventually be reflected by the ratios which proxy for the other four $C A M E L$ criteria. In an attempt to better capture the management quality, the ratio of operating expenses to total assets (EXP/TA) is used in the model development. This ratio represents operating efficiency of the management and was also used by Gonzalez-Hermosillo, Pazarbasioglu, and Billings (1997). A higher ratio reflects lower management quality and higher probability of failure.

\section{Earnings Ability}

This article uses return on assets (ROA or net income to total assets) to measure earnings ability. Return on assets is widely used as a measure of profitability (Tam and Kiang [1992]; Barr and Siems [1994]; Cole and Gunther [1995]; Hwang and Lee [1997]; Gonzalez-Hermosillo, Pazarbasioglu, and Billings [1997]). ROA is expected to be negatively related to the probability of failure.

\section{Liquidity}

Liquidity risk is the risk that depositors will withdraw their deposits in large amounts and financial institutions will not have enough liquid assets to cover these withdrawals. This article uses cash plus government securities investment to total borrowing and deposits (LIQUID) to proxy for liquidity. A large volume of liquid assets such as cash and government securities allows a finance company to meet unexpected demand from creditors. Tam and Kiang (1992) and Gonzalez-Hermosillo, Pazarbasioglu, and Billings (1997) also used a similar measure of liquidity. LIQUID is expected to be negatively related to the probability of failure.

\section{Firm Size}

Size variable (natural log of total assets) is selected because larger finance companies may have better risk diversification and better access to additional financing. They may also benefit from a "too large to fail" policy. Size variable is used by Thomson (1991), Wheelock and 
Wilson (1994), Cole and Gunther (1995) and Gonzalez-Hermosillo, Pazarbasioglu, and Billings (1997). Size is expected to have a negative relationship with the probability of failure.

\section{Reliance on Foreign-Funded Sources}

This article uses two ratios for this criterion: foreign borrowing to total borrowing and deposits (FOREIGN) and total loans to total deposits $(L O A N / D E P)$. As discussed earlier, the influx of foreign capital was one factor contributing to the failure among Thai finance companies because it exposed them to higher liquidity risk and foreign exchange risk. Since 1995, the Bank of Thailand has used LOANIDEP to assess financial institutions' reliance on foreign-funded sources. Local banks with a higher ratio than the industry average were asked to cap the ratio's growth. LOANIDEP was also used by Tam and Kiang (1992). If failed finance companies relied more on foreign borrowing (rather than on deposits) to finance loan investments, LOAN/DEP and FOREIGN would be larger among failed finance companies. On the other hand, if these companies had a poorer credit rating than surviving companies, they might not be able to obtain as much foreign borrowing as could surviving companies. In this later scenario, LOAN/DEP and FOREIGN would be smaller among failed finance companies.

\section{Empirical Models for Predicting Failed Thai Finance Firms}

This section elaborates on the methodology related to the model development and presents empirical findings. The methodology includes both univariate and multivariate tests. Annual financial data for each of the four years preceding the failure (1993, 1994, 1995 and 1996) are used to conduct these tests.

\section{A. Univariate Tests}

The univariate tests are the nonparametric Wilcoxon rank-sum tests on the nine financial variables which are relevant to the model development and are discussed in section II-B. The nonparametric tests are appropriate because several financial variables are not normally distributed. This non-normality violates an assumption of the parametric t-tests. Table 1 presents the results of the univariate Wilcoxon rank-sum tests. All significant results conform to the 
TABLE 1. Results of Wilcoxon Rank-Sum tests on Financial Aspects of Failed vs. Surviving Thai Finance Companies

\begin{tabular}{|c|c|c|c|c|c|c|c|c|}
\hline \multirow[b]{2}{*}{ Variables $^{\mathrm{a}}$} & \multicolumn{2}{|c|}{ Mean-1994 } & \multicolumn{2}{|c|}{ Mean-1995 } & \multicolumn{2}{|c|}{ Mean-1996 } & \multicolumn{2}{|c|}{ Mean-1997 } \\
\hline & Surviving & Failed & Surviving & Failed & Surviving & Failed & Surviving & Failed \\
\hline CAPITAL \% & 16.91 & 12.66 & 17.76 & 13.95 & 17.96 & 13.85 & 16.05 & 12.29 \\
\hline Wilcoxon & \multicolumn{2}{|c|}{$1.77^{* *}$} & \multicolumn{2}{|c|}{$1.74^{* *}$} & \multicolumn{2}{|c|}{$2.34^{* * *}$} & \multicolumn{2}{|r|}{$2.56^{* * *}$} \\
\hline LOAN/TA \% & 76.21 & 79.53 & 77.54 & 80.37 & 77.35 & 80.09 & 79.55 & 81.19 \\
\hline Wilcoxon & \multicolumn{2}{|c|}{$-1.48^{*}$} & \multicolumn{2}{|c|}{$-1.64^{* *}$} & \multicolumn{2}{|c|}{$-1.5^{*}$} & \multicolumn{2}{|r|}{$-1.91^{* *}$} \\
\hline BADLOAN \% & 3.43 & 4.71 & 3.65 & 4.89 & \multirow{2}{*}{\multicolumn{2}{|c|}{$\begin{array}{ll}5.00 & -1.24\end{array}$}} & 4.67 & 8.12 \\
\hline Wilcoxon & \multicolumn{2}{|c|}{-1.2} & \multicolumn{2}{|c|}{-1.15} & & & \multicolumn{2}{|c|}{$-2.68^{* * *}$} \\
\hline EXP/TA \% & 1.68 & 2.36 & \multirow{2}{*}{\multicolumn{2}{|c|}{$-1.94^{* *}$}} & \multirow{2}{*}{\multicolumn{2}{|c|}{$-2.21^{* * *}$}} & 1.56 & 2.02 \\
\hline Wilcoxon & \multicolumn{2}{|c|}{$-3.18^{* * * *}$} & & & & & \multicolumn{2}{|c|}{$-2.72^{* * *}$} \\
\hline ROA (\%) & 2.49 & 2.27 & 2.72 & 1.86 & 1.55 & .9 & 1.31 & .53 \\
\hline Wilcoxon & \multicolumn{2}{|c|}{$1.36^{*}$} & \multicolumn{2}{|c|}{$2.58^{* * *}$} & \multicolumn{2}{|c|}{$2.72^{* * * *}$} & \multicolumn{2}{|r|}{$3.86^{* * * * *}$} \\
\hline LIQUID \% & 9.18 & 8.16 & 9.22 & 7.45 & 7.21 & 7.67 & 6.53 & 7.01 \\
\hline Wilcoxon & \multicolumn{2}{|c|}{-.4} & \multicolumn{2}{|c|}{-.77} & \multicolumn{2}{|c|}{-.91} & \multicolumn{2}{|r|}{-.83} \\
\hline SIZE & 9.7 & 9.25 & 10.01 & 9.61 & 10.29 & 9.9 & 10.43 & 10.03 \\
\hline Wilcoxon & \multicolumn{2}{|c|}{$1.68^{* *}$} & \multicolumn{2}{|c|}{$1.69^{* *}$} & \multicolumn{2}{|c|}{$1.85^{* *}$} & \multicolumn{2}{|r|}{$1.91^{* *}$} \\
\hline FOREIGN \% & 8.79 & 2.49 & 8.97 & 2.85 & 12.07 & 5.39 & 12.76 & 8.4 \\
\hline Wilcoxon & \multicolumn{2}{|c|}{$2.79^{* * *}$} & \multicolumn{2}{|c|}{$3.3^{* * * * *}$} & & & & $2.56^{* * *}$ \\
\hline LOAN/DEP & 1.45 & 1.22 & 1.46 & 1.2 & 1.74 & 1.24 & 1.62 & 1.3 \\
\hline Wilcoxon & & & & & & & & $3.45^{* * * *}$ \\
\hline
\end{tabular}

Note: There are 15 surviving companies and 26 failed companies in each year. All variables are in Thai baht (39 baht is equal to approximately one dollar). All Wilcoxon rank-sum tests are one-tailed except for those for LOANDEP and FOREIGN, which are two-tailed. CAPITAL = Equity capital to total loans; LOAN/TA $=$ Total loans to total assets; BADLOAN $=$ Nonperforming loans to total loans; $\mathrm{EXP} / \mathrm{TA}=$ Operating expenses to total assets; $\mathrm{ROA}=\mathrm{Net}$ income to total assets; LIQUID $=$ Cash plus government securities investment to total borrowing and deposits; SIZE $=$ Natural log of total assets; FOREIGN = Foreign borrowing to total borrowing and deposits; LOAN/DEP = Total loans to total deposits. ${ }^{* * * * * * * * * * *, ~ r e p r e s e n t ~} .001, .01, .05$ and .10 significance levels, respectively. 
expectations. These results are listed below.

1. Failed finance companies were smaller than surviving companies, i.e., they had a significantly smaller natural log of total assets than surviving companies.

2. Failed finance companies were less profitable than surviving companies as indicated by their significantly smaller ROA.

3. Failed finance companies financed their loans with more debt than did surviving companies as indicated by their significantly smaller CAPITAL. This suggests that failed companies had lower capital adequacy.

4. Failed finance companies had lower asset quality (larger loans to total assets) as indicated by larger LOAN/TA. The BADLOAN (nonperforming loans to total loans) of failed companies is significantly larger than that of surviving companies only in 1996. This only-1996 significant result reflects the impact of the decline in Thai economy starting in 1996.

5. Failed finance companies had higher operating expenses to total assets $(E X P / T A)$. This result indicates poorer management quality among failed finance companies. It is also consistent with the Bank of Thailand's concern that these companies may have overpaid their personnel.

6. Failed finance companies had a smaller loans to deposit ratio (LOANIDEP) and less foreign borrowing (FOREIGN). This result suggests that failed finance companies had poorer credit rating than surviving companies did, hence they were not able to obtain as much foreign borrowing as surviving companies did. Therefore, the signs for LOAN/DEP and FOREIGN are expected to be negative in the subsequent logistic regression analysis, and any significance tests on these variables in the logistic models are one-tailed tests.

The comparison across the four years indicates an obvious shift in the mean of three variables for both failed and surviving companies. Particularly, there is an upward shift in the mean of BADLOAN and FOREIGN, and a dramatic downward shift in the mean of ROA. These shifts suggest more reliance on foreign borrowing and the deterioration in asset quality and profitability of both failed and surviving finance companies. These trends are consistent with the earlier discussion of reasons for problems in Thai financial institutions.

Table 2 reports the Pearson correlations of the nine financial variables which are part of the model development. The correlations are 
TABLE 2. Pearson Correlations of the Nine Financial Variables Based on the Whole Sample (41 firms).

\begin{tabular}{|c|c|c|c|c|c|c|c|c|}
\hline & $L O A N / T A$ & $B A D L O A N$ & $E X P / T A$ & $R O A$ & LIQUID & SIZE & FOREIGN & LOAN/DEP \\
\hline CAPITAL & $-.58^{* * * * * *}$ & -.13 & .03 & $.30^{* * * * * *}$ & $.23^{* * *}$ & .1 & -.03 & .08 \\
\hline LOAN/TA & & $.17^{* *}$ & .11 & $-.28^{* * * * *}$ & $-.40^{* * * * * *}$ & $-.2^{* * * *}$ & -.004 & .12 \\
\hline BADLOAN & & & $.26^{* * *}$ & $-.46^{* * * * * *}$ & $-.23^{* * *}$ & $-.21^{* * * *}$ & $-.23^{* * *}$ & $-.26^{* * * *}$ \\
\hline EXP/TA & & & & .04 & -.03 & $-.2^{* * * *}$ & $-.19^{* * * *}$ & $-.18^{* * *}$ \\
\hline ROA & & & & & $.18^{* * *}$ & .02 & .07 & .07 \\
\hline LIQUID & & & & & & $-.16^{* *}$ & -.05 & -.11 \\
\hline SIZE & & & & & & & $.47^{* * * * * *}$ & .14 \\
\hline FOREIGN & & & & & & & & $.43^{* * * * * * *}$ \\
\hline
\end{tabular}

Note: $C A P I T A L=$ Equity capital to total loans; $L O A N / T A=$ Total loans to total assets; $B A D L O A N=$ Nonperforming loans to total loans; $E X P / T A$ $=$ Operating expenses to total assets; $R O A=$ Net income to total assets; $L I Q U I D=$ Cash plus government securities investment to total borrowing and deposits; SIZE = Natural $\log$ of total assets; FOREIGN = Foreign borrowing to total borrowing and deposits; LOAN/DEP = Total loans to total deposits . ${ }^{* * * * * * * * * * * * * * * *}$ represent $0.0001,0.001,0.01$ and 0.05 significance levels, respectively. 
based upon the whole sample because it is the whole sample from which the models were developed. The knowledge of the correlations is useful for the model development because a high correlation between two important variables could be the reason why only one of the variables should enter the logistic model. The table indicates that there are seven pairs of variables with significant correlations at $<.001$ level. They are CAPITAL and LOAN/TA (-.58), FOREIGN and SIZE (.47), BADLOAN and ROA (-.46), FOREIGN and LOANIDEP (.43), LIQUID and LOAN/TA (-.4), CAPITAL and ROA (.3), and LOAN/TA and ROA $(-.28)$.

\section{B. Logistic Models}

The univariate results are only explanatory. In order to predict the failure of Thai finance companies, where failure is defined as an operational suspension in mid-1997, multivariate models must be developed. This article uses logistic regression to develop the models. The logistic regression fits linear logistic regression models for binary response data using the method of maximum likelihood. The dependent variable of the model takes the value of 1 for failing companies and 0 for surviving companies. A logistic function has the form of: $F=(1+$ $\left.\exp \left(-D_{i}\right)\right)^{-1}$, where $D_{i}=X_{i} \beta$ is a linear index of financial variables relevant to the failure. Since $F$ falls between 0 and 1, it is considered as the probability of failure.

Because of the small sample size, it is crucial to develop a parsimonious model for each of the four years (1993, 1994, 1995 and 1996). This article uses Akaike's Information Criterion (AIC) to identify these parsimonious models, i.e., to find a relatively small set of explanatory variables that minimizes AIC. Judge et al. (1985, p.870) state that the use of this criterion involves a statistic that incorporates a measure of the precision of the estimate and a measure of the rule of parsimony in the parameterization of a statistical model. ${ }^{4}$ Theodossiou et al. (1996) used AIC to identify their models. Consistent with Theodossiou et al. (1996), this article also considers the correlations of explanatory variables because the inclusion of highly correlated variables in a model could result in biased significant levels of the parameters and frequently produce statistical artifacts. In addition, the inclusion of highly correlated variables does not much enhance the

4. For further discussion and computation of AIC, see Judge et al. (1985, p.870-871) and Theodossiou et al. (1996, p.709). 
TABLE 3. Estimated Coefficients of Logistic Models for Differentiating Failed Finance Companies from Surviving Companies

\begin{tabular}{lcccc}
\hline Variables & 1993 & 1994 & 1995 & 1996 \\
\hline ROA & -.655 & -1.802 & -2.517 & -3.116 \\
Wald chi-square & $(4.106)^{* *}$ & $(5.862)^{* * *}$ & $(5.941)^{* * *}$ & $(8.525)^{* * *}$ \\
Elasticities & .406 & .523 & .546 & .712 \\
LOAN/DEP & -5.077 & -4.894 & -7.991 & -5.822 \\
Wald chi-square & $(4.24)^{* *}$ & $(4.776)^{* *}$ & $(8.401)^{* * *}$ & $(6.2)^{* * * *}$ \\
Elasticities & .414 & .485 & .69 & .598 \\
EXP/TA & 4.15 & 2.431 & 4.015 & 2.875 \\
Wald chi-square & $(7.48)^{* * *}$ & $(4.707)^{* * *}$ & $(5.895)^{* * *}$ & $(4.566)^{* * * * *}$ \\
Elasticities & .602 & .45 & .523 & .437 \\
SIZE & -.873 & -.866 & -.821 & -.942 \\
Wald chi-square & $(2.811)^{*}$ & $(3.981)^{* *}$ & $(3.889)^{* * *}$ & $(5.973)^{* * * *}$ \\
Elasticities & .301 & .386 & .379 & .561 \\
AIC & 6.506 & 6.921 & 6.177 & 5.825 \\
\hline
\end{tabular}

Note: There are 15 surviving and 26 failed companies. Akaike's Information Criterion is used to identify these models. The model's dependent variable is 1 for failed companies and 0 for surviving companies. $\mathrm{ROA}=$ Net income to total assets; $L O A N / D E P=$ Total loans to total deposits; $E X P / T A=$ Operating expenses to total assets; $S I Z E=$ Natural $\log$ of total assets. ${ }^{* * * *},{ }^{* *},{ }^{*}$ represent $.01, .05$ and .1 significance levels, respectively.

model's explanatory power. The developed logistic models have four financial variables: ROA (net income to total assets), LOANIDEP (total loans to total deposits), EXP/TA (operating expense to total assets), and SIZE (natural log of total assets). Table 3 presents these models for the four years. This table reports the parameter estimates, their Wald chisquare values, the elasticities for assessing the relative importance of variables in the models, and the $A I C$ statistics which are relatively small, ranging from 5.825 to 6.921. These relatively small AIC statistics indicate a good model fit. Across all four years, the four variables have highly significant parameter estimates. The findings and the interpretation for each variable are below.

1. $R O A$ has a negative impact on the probability of failure, meaning that failed finance companies had lower profitability.

2. $L O A N / D E P$ has a negative impact on the probability of failure, suggesting lower foreign borrowing among failed finance companies. This result indicates that failed companies had poorer credit rating in the eyes of international investors. Therefore, they were unable to obtain as much borrowing as surviving companies to 
finance their loan investments. This may also implies that foreign investors were able to somehow differentiate failed companies from surviving ones.

3. EXP/TA is positively related to the probability of failure. This suggests that failed companies' management had lower operating efficiency, and hence, lower management quality than that of surviving companies.

4. SIZE has a negative impact on the probability of failure. This means that failed finance companies were smaller than surviving companies.

These results are consistent with the prior expectations discussed in section II and are consistent with the univariate tests. Note that BADLOAN, CAPITAL, FOREIGN and LIQUID do not enter the model. The univariate tests in table 1 indicate that failed and surviving companies did not differ significantly with respect to LIQUID. As discussed earlier, BADLOAN and CAPITAL are highly correlated with ROA. BADLOAN also has higher correlation than others with EXP/TA. FOREIGN is highly correlated with SIZE and LOAN/DEP. The fact that these high-correlation variables are not in the models ensures the accuracy of the estimated parameters and the significance levels of ROA, LOANIDEP, EXP/TA, and SIZE.

To assess the relative importance of these variables, we turn to the elasticities, with higher values indicating more importance. ${ }^{5}$ The elasticities suggest that there were changes in the relative importance of the four variables over the four years. In particular, EXP/TA was the most important variable in 1993 but its relative importance declined over time and it was the least important variable in 1996. On the other hand, $R O A$ 's relative importance increased over time. It was the third important variable in 1993 and became the most important variable in 1994 and 1996. LOAN/DEP and SIZE seemed to have stable relative importance. $L O A N / D E P$ was the second important variable in three out of four years, except for 1995 when it was the most important variable. SIZE, on the other hand, was the least important variable in 1993-1995 and was the third important in 1996. In sum, these findings suggest that management quality as measured by operating expense to total assets was the most important variable in an earlier year whereas profitability was the most important in later years.

5. See Theodossiou et al. (1996, p.702) for the computation of the elasticity of logit coefficients. 


\section{Predictive Ability of the Models}

The evaluation of the predictive ability requires knowledge of the models' type I and type II error rates. Type I error rate $\left(E_{F}\right)$ is the probability of misclassifying a failing firm as surviving. Type II error rate $\left(E_{S}\right)$ is the probability of misclassifying a surviving firm as failing. However, the error rates will be biased if the models' predictive ability is tested on the same data from which they have been derived. To avoid the problem of bias in error rates, this article uses the jackknife method (Kahya and Theodossiou 1999; Altman 1981). Kahya and Theodossiou (1999) state that this method is superior to the holdout method especially for a smaller sample, because it allows the use of all available data in the estimation, resulting in a statistically more reliable model. The jackknife method, is applied as follows: (a) randomly exclude one failed and one surviving company from the estimation sample, (b) estimate the logistic model, using the sample without these two companies, (c) use this model to compute the failure scores for the excluded companies, (d) reclassify the excluded companies as either failing or surviving, (e) repeat this process 250 times, (f) determine the percentage of times the excluded failed and surviving companies are misclassified. These later percentages are unbiased estimates of the model's type I and type II errors. The optimal cutoff point for reclassification is the one that minimizes $E(C)$, the model's expected cost function.

$$
E(C)=W_{F} E_{F}+W_{S} E_{S},
$$

$W_{F}$ and $W_{S}$ are investors' specific weights attached to $E_{F}$ and $E_{S}$, respectively. The weights $W_{F}=P_{F} C_{F} /\left(P_{F} C_{F}+P_{S} C_{S}\right)$ and $W_{S}=$ $P_{S} C_{S} /\left(P_{F} C_{F}+P_{S} C_{S}\right)$ are functions of: (1) prior probabilities $P_{F}$ and $P_{S}=$ $1-P_{F}$ which measure the actual proportion of failing and surviving firms in the population, and (2) the costs $C_{F}$ and $C_{S}$ associated with the misclassification of failing and surviving firms. Kahya and Theodossiou (1999) use equal weights $\left(W_{F}=W_{S}=.5\right)$ for their U.S. sample firms. The choice of equal weights is reasonable for U.S. firms because the prior probability for failing group is smaller than that of the surviving group, whereas the cost of misclassifying failing firms is larger than that of surviving firms. However, in emerging economies, the problems with their financial institutions are likely to be more widespread, which leads to the larger prior probability for failing. 
TABLE 4. Predictive Ability of the Models Using the Optimal Cutoff Probability and the Jackknife Method with 250 Replications

\begin{tabular}{llccc}
\hline & 1993 & 1994 & 1995 & 1996 \\
\hline Cutoff Probability & \multicolumn{1}{c}{.42} & .46 & .44 & .48 \\
Type I Error & $11.6 \%$ & $7.6 \%$ & $7.6 \%$ & $4.0 \%$ \\
Type II Error & 26.8 & 26.8 & 20.00 & 13.2 \\
Cost: Weights .6 to .4 & $17.68 \%$ & $15.28 \%$ & $12.56 \%$ & $7.68 \%$ \\
Cost: Weights .7 to .3 & 16.16 & 13.36 & 11.32 & 6.76 \\
Cost: Weights .8 to .2 & 14.64 & 11.44 & 10.08 & 5.84 \\
Cost: Weights .9 to .1 & 13.12 & 9.52 & 8.84 & 4.92 \\
& & & & \\
\hline
\end{tabular}

Note: The expected costs of misclassification for four different sets of weighing (Type I to Type II errors) are also presented.

Therefore, in the absence of specific weighing, this article uses four weighing sets that have a larger weight for type I error than for type II error.

Table 4 presents the predictive ability of the models using the optimal cutoff probability and the jackknife method. The cutoff probability slightly differs across years, ranging from .42 to .48 . The comparison of type I and type II error rates indicates that both error rates decline from 1993 to 1996. In particular, type I error declines from $11.6 \%$ in 1993 to only $4 \%$ in 1996 and type II error declines from $26.8 \%$ to $13.2 \%$. Four inferences could be drawn from these results. First, the predictive ability of these models is relatively high given the small size of the estimation sample. Second, the overall predictive ability of the models improves as the time to failing becomes shorter. Third, the models perform quite better in predicting failing firms than surviving firms in each of the four years. Fourth, the improvement in the predictive ability is larger for type I error $(65.52 \%)$ than for type II error $(50.75 \%){ }^{6}$ The third and fourth inferences are especially good news since the ability to correctly identify failed finance companies is likely to be more important for investors and regulators.

The expected costs of misclassification very well reflect these inferences. The costs are relative small (ranging from $17.68 \%$ to $4.92 \%$ ) due to the small error rates. For each set of weighing, there is a significant decline in the costs from 1993 to 1996, e.g., from $17.68 \%$

6. $65.52 \%=(11.6-4.0) / 11.6 ; \quad 50.75 \%=(26.8-13.2) / 26.8$ 
(13.12\%) in 1993 to $7.68 \%$ (4.92\%) in 1996 for the weights .6 to .4 (.9 to .1). This is mainly due to the large improvement of the models' predictive ability over time. The rate of declining costs gradually enlarges as the weight of type I error increases relative to that of type II error, i.e., $56.56 \%$ for .6 to .4 weighing vs. $62.5 \%$ for .9 to .1 weighing). ${ }^{7}$ For each year, the costs also decline as the weight of type I error increases relative to that of type II error because the models have a smaller type I error rate than type II error rate. Since the higher weight of type I error could be caused by the higher actual proportion of failing firms in the population, this later result suggests that the expected costs of the models decline as the financial problems become more widespread.

This article also compared the model's predictive ability to the auditor's reports from the 1996 financial statements of sample companies. This comparison revealed that only 5 out of 26 failed finance companies (19\%) received qualified audit opinions whereas the model correctly identifies $96 \%$ of failed companies in the same year. This means $81 \%$ type I error in 1996 for the auditors versus $4 \%$ type I error for the model. There are two plausible explanations for this audit failure. First, the auditors could not effectively differentiate failed companies from surviving companies even within six months before the failure. Second, the auditors might have been skeptical about the companies' solvency problem but did not render a qualified opinion because of client pressure. Such audit failure highlights the importance of the models developed in this article as an early warning mechanism for Thai policy makers and investors. In particular, these decision makers could use the models to correctly identify a relatively high percentage of failed finance companies as early as four to three years before the failure (i.e., $88.4 \%$ in 1993 and $92.4 \%$ in 1994).

\section{Summary and Concluding Remarks}

This article uses financial variables to differentiate failed Thai finance companies from surviving companies. Failed finance companies are those which were forced to suspend their operations in mid-1997 by the Bank of Thailand. The financial variables are derived from the CAMEL criteria (Capital adequacy, Asset quality, Management quality, Earnings

7. $56.56 \%=(17.68-7.68) / 17.68 ; 62.5 \%=(13.12-4.92) / 13.12$ 
ability, and Liquidity) and previous published articles. The analyses are based on data of all 41 publicly-owned Thai finance companies from the four years preceding the failure (1993, 1994, 1995 and 1996).

The methodology includes univariate Wilcoxon rank-sum tests and multivariate logistic regression. The univariate tests indicate that failed finance companies differ significantly from surviving companies in the following respects: smaller in size, less profitable, lower capital adequacy, lower asset quality, lower management quality, and less foreign borrowing. This article uses Akaike's Information Criterion (AIC) to identify a parsimonious logistic model for each of the four years. The developed models contain four statistically significant variables: net income to total assets $(R O A)$, total loans to total deposits $(L O A N / D E P)$, operating expenses to total assets $(E X P / T A)$ and natural log of total assets (SIZE). The models indicate that ROA, LOAN/DEP and SIZE have a negative impact on the probability of failure, whereas EXP/TA has a positive impact. These findings are consistent with previous articles on financial failures.

The optimal cutoff point and the jackknife method are used to assess the predictive ability of the models. The results indicate that these models have high predictive ability, i.e., a high percentage of correct classification of both surviving and failed companies, and a relatively low expected cost of misclassification. The predictive ability improves as the time to failure becomes closer and as the weight of type I error increases relative to that of type II error. This is very much in contrast to the inability of auditors to differentiate failed finance companies from surviving ones even within six months before the failure.

Given that the parsimonious models based on publicly available information could be easily developed, some readers may question why the Bank of Thailand (BOT) was not able to make an earlier detection and correction of failed finance companies. A plausible explanation is that during the period of strong economic growth, Thai regulators tended to ignore any warning signs. Moreover, cronyism and corruption, which are widespread in Thailand and most emerging economies, accentuated the problems and deterred regulators from taking actions. Evidently, the BOT did not react until the problems got worse, which forced Thailand to seek help from the IMF. The IMF then, required Thailand to clean up its financial institutions as a condition for granting the loans. Hopefully, Thailand has learned the lessons and will become more vigilant in monitoring its financial sector. Thai policy makers (e.g., the Bank of Thailand) should seriously 
consider the use of an early warning system such as the models developed in this article.

Thailand's problems provide an invaluable lesson to emerging economies in the process of developing and improving their financial institutions and their financial reporting/disclosure systems. Since the causes of Thailand's financial problems are likely to be shared by other emerging economies, the methodology used for developing the models in this article could provide a guideline for conducting similar financial distress prediction studies of financial institutions in other emerging economies. Although this article has direct implications for international investment communities, auditors, and regulators, it has some limitations. An obvious one is the ex-post nature of the study. Other limitations include the small sample size of 41 firms and the short sample period of four years. This short period prevents the use of timeseries analysis to verify the reported results, which are based upon the cross-sectional analysis.

\section{References}

Altman, E. R. 1981. Application of Classification Techniques in Business, Banking and Finance. New York: JAI Press, Inc.

Bank of Thailand. 1997. Supervision Report 1996-97. Bangkok: Bank of Thailand Publishing Department.

Barr, R. S., and Siems, T. F. 1994. Predicting bank failure using DEA to quantify management quality. Federal Reserve Bank of Dallas Financial Industry Studies 26 (January): 1-31.

Boorman, J. 1999. Lessons from the Asian Crisis: The View from 1999. Washington D.C.: Capital Markets Research Center, McDonough School of Business, Georgetown University.

Cole, R. A., and Gunther, J. W. 1995. Separating the likelihood and timing of bank failure. Journal of Banking \& Finance 19 (September): 1073-1089.

Gonzalez-Hermosillo, B.; Pazarbasioglu, C.; and Billings, R. 1997. Determinants of banking system fragility: A case study of Mexico. International Monetary Fund Staff Papers. 44 (September): 295-314.

Hooks, L. M. 1995. Bank asset risk: Evidence from early-warning models. Contemporary Economic Policy 13 (October): 36-50.

Hwang, D. Y., and Lee, C. F. 1997. Forecasting bank failure and deposit insurance premium. International Review of Economic \& Finance 6: 317334.

Judge, G. G.; Griffiths, W. E.; Hill, R. C.; Lutkepohl, H.; and Lee, T-C. 1985. The Theory and Practice of Econometrics. New York: John Wiley and 
Sons.

Kahya, E., and Theodossiou, P. 1999. Predicting corporate financial distress: A time-series CUSUM methodology. Review of Quantitative Finance and Accounting 13:4 (December): 323-345

Ministry of Finance and Bank of Thailand. 1997. Report on Remedial Measures for Thai Financial Institution Problem. (October 14). Bangkok: Bank of Thailand Publishing Department.

Tam, K. Y., and Kiang, M. Y. 1992. Managerial applications of neural networks: The case of bank failure predictions. Management Science 38 (July): 926-947.

Theodossiou, P.; Kahya, E.; Saidi, R.; and Philippatos, G. 1996. Financial distress and corporate acquisitions: Further empirical evidence. Journal of Business Finance \& Accounting 23 (July): 699-719.

Thomson, J. B. 1991. Predicting bank failure in the 1980s. Economic ReviewFederal Reserve Bank of Cleveland 27 (1st quarter): 9-20.

Wheelock, D. C., and Wilson, P. W. 1994. Can deposit insurance increase the risk of bank failure? Federal Reserve Bank of St. Louis Review 76. (May/June): 57-71. 